\title{
Implications Of The Crisis Of Objectivity In Accounting Measurement On The Development Of Finance Theory
}

Saratiel Wedzerai Musvoto, North West University - Vaal Triangle Campus, South Africa

\begin{abstract}
Studies in accounting measurement indicate the absence of empirical relational structures that should form the basis for accounting measurement. This suggests the lack of objectivity of accounting information. Landmarks in the development of finance theory indicate the use of accounting measurement information as a basis for their development. This indicates that subjective accounting information is incorporated in finance theory. Consequently, this questions the status of finance as a universal science for all investigators, and its ability to construct precise models of finance experiences. This paper uses the principles of representational measurement to highlight the implications of subjective accounting information on the development of finance principles and concepts. It shows that finance, is not a universal science and that precise models of finance experiences are currently not constructible.
\end{abstract}

Keywords: Representational Measurement, Empirical Relational Structure, Universal Science, Finance theory

\section{INTRODUCTION}

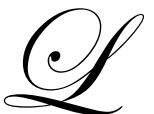

andmarks in finance theory development reflect the use of accounting information as the basic building block. For example, the mathematical economic analysis by Modigliani and Miller (1958) of capital structure reflects the model's dependency on information that is determined by accounting models. This model uses taxation figures to show that capital structure is relevant to the value of a firm in a given set of circumstances. Taxation is arrived at after allowing for expenses from the income of a firm using convention accounting rules. Thus, the taxation figure carries over accounting judgments on to the theory of capital structure. Other models such as the portfolio theory of Markowitz (1952) the capital asset pricing model (CAPM) developed by Sharpe (1964), Lintner, (1965) and Mossin, (1966) are based on the concept of return on investment. The return on an investment is arrived at after allowing for expenses on the income of the investment. Just like in determining taxation conventional accounting rules are used. This also carries over accounting judgments into these models.

Recent studies in accounting have shown that accounting information does not possess the quality of objectivity that it was thought to possess. For example, Musvoto (2008) used the principles of the representational theory of measurement to show that accounting is not a measurement discipline as was originally believed. Furthermore, other authors such as Walker and Jones (2003), Chambers (1997), Willet (1988) also reiterate the lack of foundations of measurement in accounting. Without the foundations of measurement a discipline cannot produce objective information. According to Stevens (1951) the stature of a science is commonly measured by the degree to which it makes use of mathematics. The use of the principles of mathematics produces objective information in a discipline. Measurement theory uses mathematics and thus is believed to produce objective information. Consequently, if finance theories use accounting as a basis for their development, then the lack of objectivity of accounting information also threatens their objectivity.

The discussion in this study examines the quality of accounting information that is used in the development of finance models with respect to the principles of the representational theory of measurement. This examination 
discusses a range of probably difficult issues that need clarification. The first issue covered in section 2 reviews literature on the foundational analysis the accounting concept of measurement through the principles of the representational theory of measurement. The second issue in section 3 deals with the representational measurement implications of the landmarks in the development of finance. A contrast of truth and consensus is made in section 4 while Section 5 discusses the misapplication of the uniqueness of the scale of monetary units onto the scale of value. Section 6 concludes the study.

\section{REPRESENTATIONAL MEASUREMENT AND THE SUBJECTIVITY OF ACCOUNTING INFORMATION}

Recent research in accounting has indicated that the discipline is accorded undue scientific qualities. In particular the work by Musvoto (2008) titled "Applying the representational theory of measurement to accounting" punched significant holes into the belief that accounting is a measurement discipline. The author established that current accounting measurement practices are not in harmony with the representational theory of measurement. Representational measurement theory is a theory that establishes measurement in social sciences (see, Luce et al, 1971). Musvoto (2008) classed accounting as a social science; a view that is consistent with authoritative literature on accounting and finance research methodology such as Flanders (1961) and Ryan et al, (2002). The use of representational measurement principles to conduct a foundational analysis on the accounting concept of measurement brings a new dimension to the accounting discipline. It sets up measurement standards which have for long been absent, against which measurements in accounting can be compared.

For long, users of accounting information have relied on accounting information under the premise that it is measurement information (see, Vorster et al, 2008; IASB, 2009; Ryan et al, 2002). All measurement information is expected to be objective information. As a result recent doubts expressed through the principles of representational measurement as to the objectivity of accounting information (Musvoto, 2008; Walker and Jones, 2003; Chambers, 1997) have shattered this confidence. A summary of the main principles of the representational theory of measurement that were employed in conducting the foundational analysis on the accounting concept of measurement are italicised (see, Luce and Narens, 1994) below as follows :

1) "A qualitative situation is specified by a (usually ordered) relational structure $X$ consisting of a domain $X$, of infinitely many relations of $X$ and infinitely many special elements of $X$. These relations, subsets, and elements are called the attributes of $X$. Measurement axioms are then stated in terms of the attributes of $X$. These axioms are intended to be true statements about $X$ for some empirical identification and are intended to capture important empirical properties of $X$, usually ones that prove useful in constructing measurements of its domain, $X$."

It is obvious from this quotation that an acute knowledge of the object (relational structure) of measurement is necessary before any measurement can commence. It is also inferable from the extract that a relational structure is a system that consists of a set, and a set of relations defined on the set. This relational structure is designed to capture the properties of an empirical relational structure. Evidently, every member of the set is bound by the set of relations defined on set. Furthermore, it is clear that true statements (axioms) about the empirical relational structure that are useful in constructing measurements of the elements of the empirical relational structure, should be stated. It follows that axioms are a set of qualitative laws that can be empirically tested.

This first principle is not upheld in the accounting discipline. Musvoto (2008) notes that although cost or value is specified as the objects whose properties are to be measured, there are no relational structures that specify the qualitative structures cost or value in the discipline. As a consequence it is not possible to have an acute knowledge of cost or value. Thus, it would follow that statements about cost or value cannot be judged to be true or false. It can be concluded then that current accounting statements about cost or value are vague and ambiguous.

"The representational theory requires that the primitives of $\mathrm{X}$ be given an empirical identification. In particular, if $R$ is an n-ary primitive relation on $X$, then it is required that the truth or falsity of $R(x i \ldots x n$,$) ,$ for any particular choice of the n-tuples xi, be empirically decidable." 
This excerpt points out that each identified attribute or relations of the empirical relational structure should be given an identity that can be tested empirically. It is also clear that a given proposition that is supposed to hold on an empirical relational structure should be empirically decidable. Therefore, it follows that measurements are dichotomous. That is to say, they follow the law of excluded middle. Chambers (1997) and Musvoto (2008) note that the objects of measurement (cost or value) are not given an empirical identification. Thus, cost or value is not empirically decidable.

3) "As much as possible, measurement axioms, stated in terms of the empirically identified primitives, should be empirically testable"

This extract points to the fact that all measurement propositions about the empirical relational structure should be empirically testable. It follows that if the empirical relational structure is objective, then, true statements about it must also be objective. This reflects the objective nature of all representational measurements. In relation to the accounting discipline, this means that the proposition used to assign monetary units to the value or cost of an element of the financial statements should be empirically testable. However, authors such as Ryan et al, (2002), Walker and Jones (2003), and Musvoto (2008) note that the relationship between value and monetary units is currently not known in accounting. Furthermore, it is argued that this relationship changes with an individual. Evidently, this relationship is in flux. As a result it is not empirically testable.

4) "Measurement of $\mathrm{S}$ is said to take place if and only if the following two theorems can be shown: (Existence Theorem). S (x) is non-empty for each $\mathrm{X}$ that satisfies the measurement axioms. (Uniqueness Theorem). An explicit description is provided about how the elements of $S(x)$ relate to one another. In practice this description usually consists of specifying a group of functions $\mathrm{G}$ for each 4 in $\mathrm{S}(\mathrm{x}) . \mathrm{S}(\mathrm{x})=\{\mathrm{g} * 4: \mathrm{g}$ is in $\mathrm{G})$, where * denotes function composition."

According to this excerpt the existence theorem and the uniqueness theorems are the most important principles of the representational theory of measurement. Measurement only takes place if these two theories are proved. In this case the existence theorem is satisfied once it can be shown that the property that is the subject of measurement truly exists, and that there is function (scale) that can map it onto a structure from pure mathematics. The set of all elements that defines the domain of the empirical relational structure should be not an empty set. The uniqueness theorem is satisfied if the properties of the function are known and can be empirically tested. Therefore, proving the uniqueness theorem is equivalent to specifying the unit of measurement. Hence, the unit of measurement also specifies how the elements of a particular set relate to one another with respect to that particular attribute. Since, it has been noted that cost or value cannot be proved to exist in accounting discipline (see, Musvoto, 2008), it is not possible to prove the existence theorem of representational measurement. Furthermore, this means that it is not possible to prove that the set of all elements that defines the domain of the empirical relational structure should be not an empty set. It has also been noted that the relationship that assigns monetary units to an element of the financial statements is not known in accounting (see, Ryan, et al, 2002). This means that the unit of measuring value cannot be specified with certainty. Therefore, it is not possible to prove the uniqueness theorem since it is not possible to specifying the unit of measuring value.

5) "The representational theory of measurement identifies empirical significance with meaningfulness. The concept of meaningfulness with respect to $S(X)$ is easily extended to numerical statements involving measurements of elements of the domain: meaningful statements are those whose truth-value is unaffected by the particular representation in $S(x)$ used to measure $X$."

The excerpt underlines that representational measurement takes a statement to be meaningful if it is empirically testable. This means that a proposition that is empirical or a statement that is factual, that uses algebraic or numerical quantities is meaningful empirically if and only if what it purports to represent remains the same when it is subjected to the appropriate transformations of the algebraic or numerical quantities involved. That is also to say, for example, the truth of statements about the height of a man should not be affected by the fact that it is expressed in metres or in inches. It follows that a measurement is meaningful if it is clear what statements may be made about the measure that preserve the true meaning of the measure. Evidently, these statements about the measure have to preserve the true properties of the empirical relational structure to be considered meaningful. 
Therefore, if the properties of cost or value to be measured are not known, it follows one may not know the truth or falsity of statements made about them. Furthermore value or cost has been argued to be a property in flux (see, Musvoto, 2008). This means it changes with the change in circumstances. Consequently, they cannot exhibit invariance in order to be meaningful.

\section{REPRESENTATIONAL MEASUREMENT IMPLICATIONS OF THE LANDMARKS IN THE DEVELOPMENT OF FINANCE}

In section 2 it was noted that accounting information is not measurement information with respect to the principles of representational measurement. This means that the truth of accounting information is relative to contending texts. It follows that accounting principles and concepts are not based upon the presence of pure synthetic a priori features in the subject's knowledge of the object. Consequently, for accounting information to be objective it is necessary to repossess the authentic version or the true meaning of the accounting information.

In section 1 it has been pointed out that accounting information is used as a basis for finance theories. The development of finance into a highly technical subject began with Markowitz's (1952) portfolio theory. This theory led to the operationalization of the concept of diversification in terms of portfolio variances and covariances between constituent securities. The use of accounting information is apparent in the development of portfolio theory. For example, the determination of the percentage rate of return to a portfolio reflects such use of accounting principles in the development of portfolio theory. According to Haugen (2002) the percentage rate of return of a portfolio is given by the sum of the dollar return to the securities in the portfolio divided by the amount invested. It follows that if a portfolio has two securities; $\mathbf{A}$ and $\mathbf{B}$, then the percentage return on the portfolio is given by the following expression: $\mathbf{R p}=\mathbf{W a} \times \mathbf{R a}+\mathbf{W b} \times \mathbf{R b}$; where $\mathbf{R p}$ is the percentage rate of return on a portfolio, Wa is the portfolio weight of security $\mathbf{A}, \mathbf{R a}$ is the percentage return on portfolio $\mathbf{A}, \mathbf{W b}$ is the portfolio weight of security $\mathbf{B}$, and $\mathbf{R b}$ is the percentage rate of return on security $\mathbf{B}$. An application of the principles of representational measurement theory to this concept of portfolio return reveals that the concept of a percentage rate of return on a portfolio is based on the concept of measurement that is based on structures having a natural concatenation operation that is representable by a sum and a weighted average. This concept also includes measurement structures in the combined effect of several factors on someone dimensional, ordered attribute that is representable by an additive and a polynomial combination rule. In this case, the one dimensional ordered attribute is the return on a portfolio. Furthermore, from the construction of the expression for the percentage rate of return on the portfolio, it is clear that the measurement structures of security $\mathbf{A}$ and $\mathbf{B}$ contain the measurement of the attribute "percentage rate of return of a portfolio". It is also perceivable from this that the percentage rate of return on a portfolio does not have an apparent extensive concatenation structure. Rather, it is measured by measuring the attributes of the underlying structures of the percentage return on security $\mathbf{A}$ and security $\mathbf{B}$ that affect the attribute in question. The scale value of the percentage rate of return on a portfolio is a function of the scale value of its components. This technique of measurement leads to the simultaneous measurement of the percentage rate of return on a portfolio and its components (i.e. rates of return of security $\mathbf{A}$ and $\mathbf{B}$ ). According to Luce et al (1971) the measurement of attributes that do not have an internal, additive structure, and when no extensive concatenation is apparent, that leads to the simultaneous measurement of attributes and their components is called conjoint measurement. In this case it is additive; thus, the type of measurement employed in the measurement of the percentage rate of return on a portfolio is termed additive conjoint measurement. It is also important to note that the rate of return on a security has no extensive concatenation structure that is apparent. It is calculated as the dollar return on a security divided by the amount invested in the security. Evidently, the rate of return indicates the rate of increase of the investment.

According to Ryan et al (2002) the amount invested in a security or an asset represents the value of the asset or security. Thus, it follows that the rate of return on a security indicates the rate of increase of the value of a security. Ryan et al (2002) further note that there is no agreement relating the amount of currency invested in an asset or security to a concept of value. This means that the relationship between the amount invested and value lacks empirical validity. Musvoto (2008) argues that value is a property in flux that is currently not measurable as it lacks empirical validity. From this view point it can be argued that the rates of return on different securities could reflect varying rates of increase of different constructs of value. Furthermore, given that the rate of return on a portfolio is the aggregate of the rates of return on the constituent securities multiplied by the corresponding portfolio weights, it is difficult to conceive that the aggregate rate of return on a portfolio represents a single perspective of value that 
bears empirical validity.

Luce et al (1971) argue that the application of extensive measurement to social sciences is limited by an inadequate interpretation of the concatenation operation in nonphysical attributes. The existence of an empirical operation of concatenation is a necessary condition for extensive measurement. Non-physical attributes such as value (see, Musvoto, 2008), utility and intelligence (see, Luce et al, 1971) lack an adequate interpretation for the concatenation operation. This highlights that value is a non-physical object whose numerical representations cannot be readily added unless if it can be shown that they are structurally identical. As noted above, the principle of the portfolio expected rate of return fails to recognize that numerical representations of expected rates of return should not be added unless it is established that they are structurally identical.

The portfolio theory discussed above that dealt with the individual investor's portfolio decision also provided the basis for an equilibrium asset pricing model. Sharp (1964), Lintner (1965) and Mossin (1966) developed the Capital Asset Pricing Model that is based on the portfolio theory. This model has also used the concept of return that has not received full measurement analysis as its basis. For example, consider the case of the Capital Asset Pricing Model with unlimited borrowing and lending at a risk free rate. In this case everybody in the market holds the same portfolio of risky assets. According to Haugen (2001:206) this portfolio is the efficient set that has the highest value for the following ratio:

$\underline{\mathrm{E}(\mathrm{rp})-\mathrm{rf})}$

$\mathrm{X}(\mathrm{rp})$

Where $\mathrm{E}(\mathrm{rp})$ is the expected rate of return on a portfoilio, $\mathrm{rf}$ is the risk free rate and $\mathrm{X}(\mathrm{rp})$ is the standard deviation of the portfolio expected rate of return.

In this case a measure for the efficient set is defined by three variables, the expected rate of return on a portfolio, the risk free rate and the standard deviation of the portfolio. By subtracting the risk free rate from the expected rate of return of a portfolio, it implies that these two measures are structurally identical. This operation assumes that these two variables are constructed from the concept of return that has an identical natural concatenation operation. But, as noted earlier the concept of return is based on the concept of the relationship between value and monetary units that is not known to have a natural concatenation operation. Musvoto (2008) stresses this point when he argues that monetary units have a natural concatenation operation that can be represented by natural numbers while value does not have as its empirical relational structure is currently not known. Consequently, it follows that monetary units as a representation of value do not have a natural concatenation operation. Each representation should be treated as unique. Thus, calculations involving unique representations should also be treated as unique.

Furthermore dividing the difference between the expected rate of return of a portfolio and the risk free rate by the portfolio standard deviation introduces the concept of a ratio. Belkaoui (1992:27) defines a ratio as follows: "A ratio is a measure of a specific characteristic that is obtained through laws relating the property to other properties". This quotation implies that for a ratio to exist the property that it stands for must be clearly specified. Luce et al (1990) points out that the relationship represented by a ratio must be empirically testable and it must have a natural concatenation operation. This means that the relationship that is represented by dividing the difference between the expected rate of return of a portfolio and the risk free rate by the portfolio standard deviation must have a natural concatenation operation and must be empirically testable. However, in finance this relationship that is supposed to define the efficient set of risky assets is not empirically testable and it has not received full measurement analysis to confirm the existence of a concatenation operation. If there is no reason to use such a relationship as a representation of the efficient set of risky assets then there is nothing empirical about the representation of the efficient set of risky assets that limits which monotonic transformations of this relationship can be used as indices to represent the efficient set. Nothing is lost empirically by indexing the structure of the efficient set of risky assets by for example, the square or the logarithm of dividing the difference between the expected rate of return of a portfolio and the risk free rate by the portfolio standard deviation. For the measurement of the structure of the efficient set of risky assets by this index alone, one would have at best ordinal measurement and not ratio measurement. The same is not true of structures having a natural concatenation operation since addition is used to 
represent the concatenation of intervals of these structures. The ratio character of the measurements involving structures having a natural concatenation operation is based on the numerical representation of the intervals of their structure so that the sum associated with the concatenation of adjacent intervals is the sum of values associated with those intervals. Consequently, the numerals assigned to represent the concatenation of intervals of structures having a natural concatenation operation are unique.

The discussion above highlights the fact that the finance discipline has used monetary units in measurement in accounting to develop their principles and concept without giving regard to exactly what the monetary units represent in accounting. As noted the only form of measurement that occurs in accounting is the measurement of monetary units. Value is an unknown phenomenon that has not received full measurement analysis. Thus, the common view in contemporary accounting literature that monetary units are a measure of value is false. It is therefore incorrect to suggest that the ratio scale of measuring monetary units is identical to the scale of value measurement.

\section{CONSENSUS, TRUTH AND MEASUREMENT}

In section 3 it has been noted that the finance discipline used the principles of additive conjoint measurement to model accounting information into portfolio theory. Since all measurements are expected to be objective, it follows that accounting information on which the portfolio theory is based is also expected to be objective. Consequently, such use of accounting information implicitly validates the empirically validity of accounting information. However, accounting information is based on consensus not on truth. Truth and consensus have different meanings. Bauman (1992: 232) states it as follows:

"Communal agreement, through which understanding in daily life is achieved, does not depend on the truthfulness of views of the community agrees about. The pursuit of true understanding, as distinct from ordinary agreement, must therefore detach itself from everyday discourse and seek its own rules elsewhere. What counts is not the way in which an interpretation has been reached, but the way in which its objective validity may be defended and -ideally-proved. Only if this way is found can the interpretation be awarded the authority required in relation to alternative interpretations which cannot be so defended."

It is clear from this that the rules that guide the process of reaching communal agreement are different from the rules that are used in establishing the empirical validity of proposed truths. It is also evident from this that the pursuit of truth dictates the need for rules that would make the determination of truth independent of particular places and factual occurrences. Thus, truth is not relative rather its objective validity must be defensible in all frames of reference. It important to note that accounting information is produced under the principles of International Accounting Standards, Generally Accepted Accounting Principles or some other standard that accountants have agreed upon. These agreements by accountants reflect consensus not the truth. Consequently, it is not prudent it use accounting information under the premise that its objective without proving it. If accounting information is ambiguous (see, Musvoto, 2008) then, the activity of determining accounting information is not an autonomous, self-sustained and self-governed realm. Thus, the way in which the objective validity of accounting information may be defended and -ideally-proved cannot be established. Therefore, the current interpretation of accounting information cannot be awarded the authority required in relation to alternative interpretations of it which cannot be so defended.

In some frames of reference such as South Africa financial statements should comply with the requirements of the companies Act of 1973 and Schedule 4 and conform to generally accepted accounting practice (see, Musvoto, 2008). It is clear from this that the law enforces the preparation of the principles of generally accepted accounting practice. That is, it enforces preparation according to the consensus of various accounting practitioners in a specific community of discussion. This indicates that the preparation if the financial statements is based on a form of communal agreement. Therefore, it can be argued that as a result of the possible reprisal from the law one cannot accept this resulting consensus as reflecting the rational will of accountants on the nature of accounting information. It is not possible for such a consensus to reflect rational will if the negotiations leading to it were not allowed to come under the argumentative scrutiny of the accountants and accepted on their own merit. In this case, the powerful authority has lent its support for the principles of GAAP. As a result accountants are prevented from 
considering alternative accounting norms and treatments. It follows that in cases were a powerful authority lends its support, it is important to distinguish truth from consensus.

Furthermore, given that the accounting entity is generally viewed as an economic unity under one management, and the scope of the management's power determines the boundaries of the entity (Staubus, 1985), it is clear from this that the meaning of accounting information from different entities could hardly be identical. The meaning of accounting information is from different settings and for this reason one cannot understand the accounting texts (financial statements) from different entities in the same way. The meanings from these financial statements diverge. Some financial statements have to be subtler, richer and more ambiguous than others. The images, the phrases, the words of some financial statements soak and absorb unique emotions and enter into unique associations. The objective alternatives confronting one firm are not those faced by another; thus identical choices of different firms cannot but have different meanings. From the concept of opportunity cost, it would follow that choices owe their meanings to the choices they leave behind. That is the alternatives they objectively reject. Each observer gives an account of financial statements wearing the mask that is reminiscent of their culture.

\section{THE MISAPPLICATION OF THE UNIQUENESS OF THE SCALE OF MONETARY UNITS ONTO THE SCALE OF VALUE}

The assignment of monetary units to the value of an element of the financial statements requires that the accountant matches the attribute of value in the empirical relational structure of value with the attribute of monetary units in the empirical relational structure of money. This means that there should be two physical structures one for value and the other for monetary units; given, that monetary units as the representing structure are an extensive structure, then, each of these physical structures should have a ratio scale representation. Since, Musvoto (2008) points out that there is no specified relation that relates value to monetary units it means that there are two possible physical relational structures that are connected by a purely psychological relation. Furthermore, Musvoto (2008) also asserts that value is a hypothetical phenomenon that has not received full measurement analysis. This suggests that there is one physical relational structure connected to a hypothetical phenomenon by a psychological relation. It follows that in the accounting discipline it is necessary to specify the domain of value and the domain of monetary units before matching can occur between the members of these two domains. If value is a hypothetical phenomenon as outlined above, then it means that the compatibility between the domain of value and monetary units cannot currently be described as value is not a physical structure. Musvoto (2008: 147) states it as follows:

"It should also be noted that the ratio scale character of the monetary unit measurement is based on the numerical representation of monetary unit intervals so that the value associated with the concatenation of adjacent intervals is the sum of values associated with those intervals. However, this does not mean that the number of monetary units as a measure of accounting value is also a ratio scale. The subdivision of the amount of currency paid for a commodity into small intervals defined by the monetary unit has, as far as is known, nothing empirically to do with exchange value".

This means that a fundamental measurement can only result if there is an explicit theory of the measurement of all the variables involved in the process of measurement. That is to say, there must be a separate theory for measurement of each of value and monetary units. Furthermore, there must be a theory of measurement that connects the entire separate measurable variables involved in the measurement value. In the absence of such a theory it would not be possible to measure value using monetary units. The uniqueness theorem of representational measurement can only be proved on the measurement of monetary units, but it cannot be proved on the measurement of value. In this case, the uniqueness of the scale of monetary units has been misapplied onto the scale of value.

\section{SUMMARY AND CONCLUSIONS}

The discussion above highlights that despite the development of finance into a highly technical discipline, its principles and concepts have been based on subjective accounting foundations. Cost and value which have been specified as the objects of measurement in accounting are indeterminate. This has lead to the production of accounting information that is not objective. These two concepts have been used as a basis for the development of 
the portfolio theory that forms the basis of all finance principles and models. Consequently, this has resulted in the use of subjective accounting information by the finance discipline.

It is also clear that the development of the portfolio theory employs the principles of fundamental measurement of the representational theory of measurement. In particular it employs the principles of additive conjoint measurement in determining the rate of return on a portfolio. However, this has been done in the absence of an explicit theory that measures all the variables involved. The end result has been the misapplication of the uniqueness of the scale of monetary units onto the scale of value. For this reason, finance cannot be a universal science for all investigators. In addition to this the finance discipline has not distinguished between information that is based on consensus and that which is based on truth. In the end information that is subjective has been mistaken for empirically valid information. This compromises the reliability of finance models.

\section{AUTHOR INFORMATION}

S Wedzerai Musvoto, $\mathrm{PhD}$ is a senior lecturer in Financial Management and Accounting at the School of Accounting Sciences of the North-West University's Vaal Triangle Campus. He received his PhD from the University of Pretoria in 2008. Dr Musvoto is also affiliated with the Association of Chartered Certified Accountants and the Chartered Institute of Management Accountants. His research interests include accounting measurement, risk management and the implications of modern principles of measurement on finance theory development.

\section{BIBLIOGRAPHY}

1. Bauman, Z. (1992) "Hermeneutics and Social Science, Approaches to Understanding”, Gregg Revivals, USA

2. Belkaoui, A. (1992). Accounting Theory, Academic Press Limited.

3. Chambers, R.J. (1997) "Wanted: Foundations of Accounting Measurement", Abacus, 34(1): 36-47

4. Flanders, D., P. (1961) “Accountancy, Systematized Learning, and Economics”. The Accounting Review, 36: 564-576.

5. Haugen, R.A (2001)" Morden Investment Theory $5^{\text {th }}$ edition”, Prentice Hall International, Inc

6. International Accounting Standards Board (IASB), 2009, International Financial Reporting Standards (IFRS), 2009: Including International Accounting Standards (IAS) and interpretations as at 1 January 2009.

7. Lintner, J. (1965) "The Valuation of Risky Assets and the Selection of Risky Investments in Stock Portfolios and Capital Budgets," Review of Economics and Statistics, February

8. Luce, R, D. and Narens, L. (1994) "Fifteen Problems Concerning The Representational Theory of Measurement". Available, http:// www. Imbs.uci.edu / personnel / Luce / 1994/ Luce \& Narens_Book \% 20 Chapter_1994.pdf, Accessed 2006/10/10

9. $\quad$ Luce, R. D.; Krantz, D.H.; Suppes, P. \& Tversk, A. (1989) “Foundations of Measurement, (Vol. 2) Geometrical, threshold, and probabilistic representations", New York: Academic Press

10. Luce, R. D.; Krantz, D.H.; Suppes, P. \& Tversk, A. (1990) "Foundations of Measurement, (Vol. 3) Representations, axiomatization, and invariance", New York: Academic Press

11. Luce, R. D.; Krantz, D.H.; Suppes, P. \& Tversk, A. (1971) "Foundations of Measurement, (Vol. 1) Additive and Polynomial representations", New York: Academic Press

12. Markowitz, H.M. (1952). "Portfolio Selection “, Journal of Finance, December

13. Mossin, J. (1966) "Equilibrium in a Capital Market, "Econometrica, October

14. Musvoto, S.W (2008) "Applying the representational theory of measurement to accounting", $\mathrm{PhD}$ thesis, University of Pretoria, Pretoria, Viewed yymmdd $<$ http://upetd.up.ac.za/thesis/available/etd-03282009$\underline{125051 />}$

15. Ryan, B., Scapens, R.W., and Theobald, M. (2002) "Research Method and Methodology in finance and Accounting", Second Edition, Mitcham, Surrey, International, Padstow, Cornwall

16. Sharpe, W. F. (1964) "Capital Asset Prices: A Theory of Market Equilibrium, “Journal of Finance, September

17. Staubus, G. J. (1985). “An induced Theory of Accounting Measurement”, The Accounting Review, January, 60(1): 53-75. 
18. Stevens, S.S. (1951) "Mathematics, Measurement and psychophysics, in (Ed), Handbook of Experimental psychology", New York: Wiley

19. Vorster, Q., Koornhof, C., Oberholster, J., Koppeschaar, Z., Coetzee, S., Janse van Rensburg, C. and Binnekade, C. (2008) "Introduction to IFRS", Lexis Nexis, Durban

20. Walker, R.G. and Jones, S. (2003). Measurement: "A way forward", Abacus: 39 (3): 356-374.

21. Willet, R.J. (1988) "An Axiomatic Theory of Accounting Measurement - Part 2", Accounting and Business Research, 19(73): 79-91. 


\section{NOTES}

